\title{
On Systemically Important Financial Institutions and Progressive Systemic Mitigation
}

James B. Thomson

Follow this and additional works at: https://via.library.depaul.edu/bclj

\section{Recommended Citation}

James B. Thomson, On Systemically Important Financial Institutions and Progressive Systemic Mitigation, 8 DePaul Bus. \& Com. L.J. 135 (2010)

Available at: https://via.library.depaul.edu/bclj/vol8/iss2/3

This Article is brought to you for free and open access by the College of Law at Digital Commons@DePaul. It has been accepted for inclusion in DePaul Business and Commercial Law Journal by an authorized editor of Digital Commons@DePaul. For more information, please contact digitalservices@depaul.edu. 


\title{
On Systemically Important Financial Institutions and Progressive Systemic Mitigation
}

\author{
James B. Thomson*
}

\begin{abstract}
One of the most important issues in the regulatory reform debate is the systematic importance of certain financial institutions. This Article proposes a framework for identifying and supervising such institutions. The framework is designed to remove the advantages they derive from becoming systemically important and to give them more time-consistent incentives. It defines the "four C's" of systemic importance (contagion, concentration, correlation, and conditions) as criteria for classifying firms as systemically important that goes beyond binary classification based on size alone (the classic doctrine of too-big-to-fail). This Article also discusses the concept of progressive systemic mitigation.
\end{abstract}

\section{Systemically Important Financial Institutions and Progressive Systemic Mitigation}

Central banks increasingly define financial stability as a key mission, second only to monetary policy. Achieving financial stability involves promoting time-consistent incentives for financial firms and other market participants. Getting the incentives right requires supervisors to deal with systemic risk and, in particular, systemically important financial institutions. Establishing a financial stability supervisor alone will not achieve stability; it is also crucial to deal proactively with systemically important financial institutions. To do so, it is necessary to have a workable definition of "systemically important."

On one level, the definition is fairly simple. A firm is considered systemically important if its failure would have economically significant spillover effects, which could destabilize the financial system and

* Vice President and Financial Economist in the Research Department at the Federal Reserve Bank of Cleveland. The views expressed here are those of the author and not necessarily those of the Federal Reserve Bank of Cleveland, the Board of Governors of the Federal Reserve System, or their respective staffs. The author thanks the regulatory reform workgroup at the Federal Reserve Bank of Cleveland (Jean Burson, Emre Ergungor, Mark Greenlee, Joe Haubrich, Paul Kaboth, Dan Littman, Steve Ong, and Andy Watts) for their thoughtful contributions to this work, as well as Ed Kane, Viral Acharya, Bill Osterberg, George Pennacchi, Mark Sniderman, and Walker Todd for their insightful comments and suggestions. Any errors are the responsibility of the author. 
have a negative impact on the real economy. This definition is unsatisfactory because it provides little guidance in practice. What is needed is a workable definition of "systemically important." However, because a variety of factors could make a firm systemically important, a one-size-fits-all definition is not very useful.

What can be gained from putting parameters around the term? Delineating the factors that might make a financial institution systemically important is the first step towards managing the risk arising from it. Understanding why a firm might be systemically important is necessary to establish measures that reduce the number of systematically important firms and develop procedures for resolving the insolvency of such firms at the lowest total cost (including the long-run cost) to the economy. This, of course, involves careful consideration of the types of resolution authority needed, the funding source for operating any such authority, and the related infrastructure. While a credible resolution process should involve addressing contingency plans as part of the supervisory regime, the discussion of the type and form of resolution authority is left to a companion article.

This Article aims to establish a set of criteria for designating financial firms as systemically important. First, the sources of systemic risk are identified through the consideration of how a financial institution becomes systemically important. Regarding systemic importance as a continuum rather than a binary distinction, this Article then investigates the usefulness of establishing categories of systemic importance and the trade-off between a manageable definition and the number of categories used to classify financial institutions. Next, this Article discusses the establishment of a list of systemically important financial institutions, weighs the merits of making such a list public, and offers criteria for categorizing institutions. This Article then concludes with policy recommendations.

\section{Defining Systemically Important Financial Institutions}

The purpose of creating a practical definition of systemic importance is to enable supervisors to discipline systemically important financial institutions. Understanding the nature and causes of systemic importance is the foundation for creating regulations, supervisory policies, and infrastructure that will rein in the associated systemic risk. In some cases, doing so sufficiently mitigates an institution's potential systemic impact so that it would no longer be considered systemically important. Because any two firms could be deemed systemically important for unrelated reasons, a one-size-fits-all designation such as 
"too-big-to-fail" is inadequate. ${ }^{1}$ Consequently, the approach taken here proposes a means of classifying systemically important financial institutions ("SIFIs").

\section{A. Size}

Size alone is not an adequate criterion for classifying institutions as systemically important. While a size threshold is the simplest way to categorize SIFIs - whether it be asset-based, activity-based, or bothit is potentially the most flawed method for doing so. Ideally, a sizebased classification should account for not just the level of activity, but also for the nature of the financial institution's activities. For instance, a bank with five-percent of assets nationwide that holds a portfolio largely consisting of government and agency securities is likely to have less serious systemic implications than a comparable bank with a portfolio of commercial and industrial loans. After all, absent embezzlement and fraud, the bank holding mostly low-risk, marketable securities will be less likely to fail, and will cause less serious consequences if it does fail, than the bank holding more opaque, riskier commercial and industrial loans. Further, off-balance-sheet activities might also need to be accounted for. Credit substitutes, such as letters of credit and lines of credit, are rightfully included in financial firms' credit-intermediation activities. Moreover, it is important to define SIFIs in a way that minimizes unintended consequences, such as reducing market discipline on firms added to the SIFI list.

Although the size threshold could certainly be set low enough to capture most of the firms that are systemically important for other reasons, the majority would not be systemically important. Including these firms would put too heavy a burden on them. One objective of defining systemically important institutions is to allow differential regulatory taxes, or user fees, across types. Efficiency and equity concerns therefore require more flexible definitions. The definitions presented are based on four factors other than size, which, individually or collectively, can make a financial institution systemically important. These are the "four C's" of systemic importance: contagion, correlation, concentration, and conditions (context).

As a starting point for a size-based definition, a conglomerate financial firm would be considered systemically important if it accounts for at least ten-percent of the activities or assets of a principal financial

1. The first incarnation of the SIFI philosophy of "too-big-to-fail" dates back to the FDIC bailout of the Continental Illinois Bank and Trust Company of Chicago in 1984. See generally Irvine H. Sprague, Bailout: An Insider's Account of Bank Failures and Rescues (Basic Books 1986) (discussing the failure and rescue of Continental Illinois). 
sector or financial market, or five-percent of the total financial market's activities or assets. ${ }^{2}$ Using current financial-sector designations as a guide, a SIFI would satisfy any of the following criteria. ${ }^{3}$

- The consolidated entity holds ten-percent or more of nationwide banking assets, or has five-percent of nationwide banking assets and fifteen-percent or more of loans.

- After converting off-balance-sheet activities into balance-sheet equivalents, the consolidated entity holds ten-percent or more of nationwide banking assets. Off-balance-sheet items would include, for instance, items from schedule RC-L from the FFIEC Reports of Condition and Income and HC-L from the Federal Reserve Y9 reports ${ }^{4}$; structured investment vehicles and other loan special purpose entities used to remove assets from the firm's balance sheet for regulatory capital purposes; and assets sold or securitized. ${ }^{5}$

- The consolidated entity accounts for ten-percent of the total number or total value of life insurance products (whole and universal life policies and annuities) nationwide.

- The consolidated entity accounts for fifteen-percent of the total number or total value of all insurance products (whole and universal life policies, property and casualty policies, annuities, etc.) nationwide.

- A non-bank financial institution other than a traditional insurance company (one that underwrites and prices its products using actuarially sound principles) such as an investment bank might be considered systemically important if:

- its total asset holdings would rank it as one of the 10 largest banks in the country;

- its total assets would rank it in the top 20 largest banks and its adjusted total assets (accounting for off-balance sheet activities) would rank it in the top 10 largest banks; or

- it accounted for more than twenty-percent of securities underwritten (averaged over the previous five years).

2. These standards could be established on a book or fair-market basis. Ideally, SIFI thresholds would be determined using fair-value accounting as far as possible.

3. These are examples of possible thresholds; however, any proposed system of thresholds must be vetted and, if possible, established (and periodically updated) on the basis of empirical studies.

4. Federal Deposit Insurance Corporation, Schedule RC-L, Off-Balance Sheet Items, available at http://www.fdic.gov/regulations/resources/call/crinst/398rc-l.pdf.

5. It might be prudent to apply the adjusted-asset test only to financial institutions that hold more than five-percent of U.S. banking assets. 


\section{B. Contagion}

The two classic cases of contagion as a source of systemic importance are failures of Herstatt Bank in 1974 and Continental Illinois in 1984. ${ }^{6}$ Although Herstatt was a relatively small institution, its closing had the potential to disrupt the international payments system and imposed nontrivial losses on its counterparts. As discussed by Todd and Thomson, the stated rationale for the FDIC bailout of all Continental Illinois's creditors was the threat that losses would be transmitted to some 2,300 community banks that had correspondent-banking relationships with Continental. ${ }^{7}$ Most recently, the justification for the Federal Reserve of New York's assisted acquisition of Bear Stearns by JPMorgan Chase appears to have been concerns about contagion. ${ }^{8}$ In this case, the source of contagion was the potential for loss transmission through the credit-default-swaps market. In principle, the ability to put parameters around contagion as source of systemic importance should enable effective treatments to mitigate contagion.

A financial institution would be considered systemically important if its failure could result in:

- substantial capital impairment of institutions accounting for a combined thirty-percent of the assets of the financial system;

- the locking up or material impairment of essential payments systems (domestic or international); or

- the collapse or freezing up of one or more important financial markets.

A substantial impairment of a payments system or market would be one that is large or long enough to affect real economic activity. ${ }^{9}$

\section{Correlation}

Correlation as a source of systemic importance is also known as the "too-many-to-fail" problem. ${ }^{10}$ Penati and Protopapadakis show how correlated risk exposure contributed to the overexposure of large U.S.

6. Walker F. Todd \& James B. Thomson, An Insider's View of the Political Economy of the Too Big to Let Fail Doctrine (Fed. Res. Bank of Cleveland, Working Paper No. 9017, 1990).

7. Id. at 18-19.

8. Board of Governors of the Federal Reserve System, Monetary Policy Report, Feb. 24, 2009 , available at http://www.federalreserve.gov/monetarypolicy/mpr_20090225_appendixa.htm.

9. It is important that studies be performed in order to define the parameters of a material or substantial disruption of the payments system carefully.

10. See generally Janet Mitchell, Strategic Creditor Passivity, Regulation, and Bank Bailouts (CEPR discussion paper no. 1780, 1988) (discussing the "too-many-to-fail" problem) 
banks to borrowers in developing countries.11 There are two important aspects of correlation risk. First, the institutions have the incentive to take on risks that are highly correlated with other institutions because policymakers are less likely to close an institution if many other institutions would become decapitalized at the same time. This is consistent with the casual observation of herding behavior in the financial system which, in the most recent episode, took the form of financial institutions overexposing themselves to subprime mortgages, mortgage-backed securities, and related mortgage-derivative securities. Second, the potential exists for largely uncorrelated risk exposures to become highly correlated in periods of financial stress. Andrew Lo designated this phenomenon as "phase-locking behavior."12 This means that a group of institutions that would not typically pose a systemic threat might, in certain economic or financial-market conditions, become systemically important. The 1980s savings and loan debacle in the United States is an example of this. ${ }^{13}$ As most of the savings and loan industry was exposed to interest-rate risk, the interest-rate shocks of the late 1970 s and early 1980 s decapitalized the majority of institutions. ${ }^{14}$ This second form of correlation-driven systemic importance is actually an example of condition- or contextdriven systemic importance.

The "too-many-to-fail" problem is a bit more difficult because it requires that a group or subset of institutions be classified as jointly systemic. As in the case of contagion, putting parameters around correlated risk exposure, including determining what level of correlation across portfolios and volatility of exposure poses a systemic threat, is the first step towards developing and implementing regulatory treatments. Classifying institutions as systemically important because of correlated risks would result in developing and estimating risk models, using stress testing and scenario analysis, and establishing a set of fundamental risk exposures that financial institutions' portfolios could be mapped into. Fortunately, some large financial institutions are doing this type of risk modeling and scenario analysis for looking at their own risk profile. This analysis provides a good foundation for others to work from. Moreover, academic economists have begun to think

11. See generally Alessandro Penati and Aris Protopapadakis, The Effect of Implicit Deposit Insurance on Banks' Portfolio Choices with an Application to International Overexposure, $21 \mathrm{~J}$. of Monetary ECON. 107 (1988); see generally Janet Mitchell, supra note 9.

12. See Andrew W. Lo, Hedge Funds: An Analytic Perspective 18-22 (Princeton Univ. Press. 2008).

13. Id. at 18.

14. See Edward J. Kane, The S\&l Insurance Mess: How Did it Happen? 63-92 (The Urban Institute 1989). 
about modeling macro-financial risks in the economy, a step towards modeling and quantifying correlated-risk exposure. ${ }^{15}$

What levels of correlated risks would give rise to systemic concerns? The following thresholds would make groups of institutions systemically important.

- The probability that an economic or financial shock would decapitalize institutions accounting, in aggregate, for thirty-five percent of financial system assets or twenty-percent of banking assets.

- Potential for economic/financial shock to decapitalize institutions accounting, in aggregate, for fifteen-percent of financial system assets or ten-percent of banking assets, and for nationwide shares amounting to:

- fifteen-percent of wholesale or retail payments;

- thirty-five percent of a major credit activity;16

- fifty-percent of securities processing or thirty-percent of securities underwriting (five-year average);

- twenty-percent of the total number or total value of life insurance products (universal and whole life policies and annuities); or

- thirty-percent of the total number or total value of insurance products (whole and universal life policies, property and casualty policies, annuities, etc.).

\section{Concentration}

Presence by dominant firms in key financial markets or activities can give rise to systemic importance if the failure of one of these firms could materially disrupt or lock up the market. Concentration has two important aspects: the size of the firm's activities relative to the market and the contestability of the market. That is, concentration is less likely to make a financial institution systemically important if, other things being equal, the activities of a distressed institution can easily be assumed by a new entrant into the market or by the expansion of an incumbent firm's activities. Hence, it is logical to adjust concentration thresholds to account for contestability.

15. See, e.g., Dale F. Gray et al., A New Framework for Analyzing and Managing Macrofinancial Risks of an Economy (NBER, Working Paper No. 12637, 2006), available at http://www.nber.org/papers/w12637.

16. Fairly broad definitions of credit activities should be used. For example, the categories might include commercial credit, housing finance, small-business credit, agricultural credit, and consumer credit. Moreover, it is necessary to establish a threshold for categorizing a credit activity as major. 
A financial institution is systemically important if its failure could materially disrupt a financial market or payments system. This causes economically significant spillover effects that impede the functioning of broader financial markets and/or the real economy. Thresholds for concentration that would render a financial institution systemically important include any firm (on a consolidated basis) that:

- clears and settles more than twenty-five percent of trades in a key financial market;

- processes more than twenty-five percent of the daily volume of an essential payments system; or

- is responsible for more than thirty-percent of an important credit activity.

\section{E. Conditions/Context}

In certain states of nature or some macro-financial conditions, closure policy may not be independent of these conditions. In other words, regulators are reluctant to allow the official failure (closure) of a distressed financial institution under particular economic or financial market conditions if its solvency could have been resolved under more normal conditions. Hence, conditions/context are sources of systemic importance. For instance, Haubrich notes that the New York Federal Reserve's reluctance to allow the failure of Long-Term Capital Management ("LTCM") resulted largely from the fragility of financial markets at that time-due to the Southeast Asian currency crises and the Russian default. ${ }^{17}$ This might explain, in part, why LTCM was treated as systemically important and Amaranth (which was more than twice as big) was not. Another example would be the intervention by the government to prevent the bankruptcy of Bear Stearns by merging it (with assistance) into JPMorgan Chase in early 2008, whereas Drexel Burnham Lambert was allowed to enter bankruptcy in early $1990 . .^{18}$

Firms that might be made systemically important by conditions/context are probably the most difficult to identify in advance. Certainly, stress testing and scenario analysis will be needed to identify them. As discussed above, during periods of financial market distress, phaselocking behavior can cause what would otherwise be slightly corre-

17. It is worth noting that the LTCM rescue was a temporary measure designed to wind down the affairs of LTCM in an orderly fashion, a kind of prepackage bankruptcy. See generally Joseph G. Haubrich, Some Lessons on the Rescue of Long-Term Capital Management 3 (Fed. Res. Bank of Cleveland, Policy Discussion Paper No. 19, 2007) (discussing the rescue of LTCM).

18. Stephen Labathon, The Collapse of Drexel Burnham Lambert; The Firm Is Not Expected to Survive, N.Y. TIMEs, Feb. 14, 1990. 
lated risk exposures to become highly correlated. ${ }^{19}$ As a result, a group of institutions that would not pose a systemic threat under normal economic or financial-market conditions become systemically important.

Two sets of criteria must be established to classify firms that are systemically important because of context. First, the probability that economic or financial conditions will materialize can produce the state of nature where a firm or group of firms becomes systemically important. Second, the thresholds for systemic importance, which presumably would be based on those used to classify SIFIs according to contagion, concentration, and correlation during normal market conditions. Which thresholds are applied would depend on which type of systemic importance the conditions produce.

\section{Establishing SIFI CAtegories}

One method to classify systemically important financial institutions was suggested in the Geneva report. ${ }^{20}$ Institutions may be systemic on their own, as part of group, or in a particular context (or state of the economy). ${ }^{21}$ Under this classification scheme, there would likely be four or five categories of institutions. Category four would consist of large, but not overly complex, regional financial institutions. Category five would consist of community financial institutions. Institutions could migrate between categories as their activities and risks evolve.

Constructing categories permits application of the modern tax principles of horizontal and vertical equity in regulating FISIs. Within each category, every financial institution would be subject to equivalent regulatory treatment and intensity of supervision. Of course, because two institutions could fall under the same category for different reasons, the exact forms of their regulatory taxes would logically differ. In this case, equitable treatment consists of the same degree of regulatory interference (level of regulatory taxes), although the forms of regulation may not be exactly the same. As firms move up the categories, firms would be subject to increased levels of regulatory interference and supervisory attention-that is, progressive systemic mitigation-analogous to the prompt corrective action

19. Lo, supra note 11.

20. Markus Brunnermeier et al., The Fundamental Principles of Financial Regulation, 2009 Geneva Reports on the World Economy 11 (January 6, 2009) (unpublished position paper), available at http://www.princeton.edu/ markus/research/papers/Geneva11.pdf.

21. Id. 
provisions of the Federal Deposit Insurance Corporation Improvement Act of 1991.22

Increased regulatory taxes and supervisory scrutiny for higher categories can be justified in terms of economic efficiency and equity. For instance, economic efficiency dictates that regulatory taxes increase to the point where the cost of the last increment of these taxes equals the benefit of imposing them. It is likely that the cost of complying with additional regulations is inversely related an institution's size and complexity, while the benefits from additional regulation are directly related. Hence, as institutions become larger and more complex, increased regulation and more intensive supervision may be consistent with economic efficiency. Furthermore, to the extent that the wedge between the private and social costs of failure is related to an institution's size and complexity, economic efficiency demands graduated sets of regulatory taxes, which are designed to internalize the externalities.

There are equally compelling arguments for progressively intensive or intrusive regulatory treatments on the grounds of equity as firms move up the systemic category ladder. One such is the "level playing field" argument: to the extent that systemic importance confers competitive advantages on an institution, equity concerns would dictate a system of graduated regulatory taxes to remove (or at least minimize) the advantages of being (or becoming) systemically important.

Of the five categories, only three would contain financial institutions that are considered systemically important. The rationale for a five-category system is that it allows for more consistent application of regulatory taxes and supervisory oversight across categories, following the notion that differential supervision and regulation can level the playing field by mitigating the advantages financial institutions derive from systemic importance. ${ }^{23}$ The categories would likely be defined as follows:

\section{Category 1}

Financial institutions that would be considered SIFIs on the basis of size alone (the classic "too-big-to-fail" category) or due to concentra-

22. Federal Deposit Insurance Corporation Improvement Act of 1991, 12 U.S.C. $\S 1811$ (1991).

23. Another rationale for systemic categories is the degree to which markets can, or would be, allowed to discipline systemic institutions can differ across categories, with higher categories containing financial institutions where market discipline is less likely to be effective (or those that are allowed to operate unfettered). 
tion (the firm is a dominant player in an economically significant financial market or activity).

\section{Category 2}

Financial institutions that are systemically important because of interconnectedness (interbank or inter-firm exposure, also known as contagion).

\section{Category 3}

Financial institutions that are systemically important as a group because of correlated risk exposures (the "too-many-to-fail" problem). Also included in this category would be financial institutions that are systemically important because of conditions or context.

\section{Category 4}

Large financial institutions that are not systemically important but whose failure could have economically significant implications for regional economies. This category would include large regional banking companies and large insurance companies.

\section{Category 5}

Financial institutions not included in the other categories, consisting primarily of community financial institutions.

Under the philosophy of progressive systemic mitigation, institutions in category five would be subject to a basic level of safety-andsoundness regulation and supervisory oversight. No special reporting requirements, targeted risk exams, or other treatments would be necessary. ${ }^{24}$ Category four institutions would not face any special capital surcharges or activity restrictions that might apply in categories one through three, but they would be subject to additional reporting requirements and expected to implement risk management systems and more sophisticated risk controls than category five institutions. Moreover, category four institutions would be subject to more vigorous supervision than those in category five. ${ }^{25}$

24. These institutions would remain subject to consumer regulation.

25. Recently, the Federal Reserve Bank of Cleveland President Sandra Pianalto outlined a new regulatory scheme called "tiered parity." In this scheme, financial firms would be separated into three classes or tiers based upon their complexity. As in the present proposal, regulatory treatment of a firm would be determined by which tier it is assigned to (with equal regulatory treatment of firms within a tier). To go from the five-category progressive systemic mitigation scheme to the three tiers of the tiered parity scheme, you simply combine categories 4 and 5 in tier 3 and categories 2 and 3 in tier 2 . Category 1 of progressive systemic mitigation is essentially 
At a minimum, category three institutions should be subject to routine stress tests and be required to have contingency plans in place. Regulatory agencies need to conduct routine scenario analysis and simulations to ascertain the financial system's vulnerability to a correlated-risk event and establish the appropriate regulatory treatment. Such treatment might include actions like portfolio limits, add-on capital requirements, and loss reserves tied to the activities driving the correlated risks. Scenario analysis and risk simulations would be used as part of contingency plans for handling correlated risk events. Stress tests, scenario analysis, risk simulations, and contingency plans would also be part of the operational regulatory system for dealing with institutions that are rendered systemically important by conditions or context.

Progressive systemic mitigation implies that the treatments adopted for category three institutions should also be applied to those in categories one and two. For category two institutions, it is necessary to establish regulatory reporting requirements that allow for inter-bank/ inter-firm exposures, both direct and indirect, to be tracked and measured. In addition, limits on direct and indirect exposure to counterparties should be instituted, along with specific reserves and add-on capital charges designed to limit contagion across firms. For category one institutions, two more types of regulatory treatment need to be added to those faced by category two institutions. First, market discipline should be enhanced through mandatory debt-structure requirements, which could include a mandatory subordinated debt requirement and/or reverse convertible debentures. ${ }^{26}$ Moreover, a system of double indemnity for shareholders in category one institutions could be an effective device for providing socially compatible incentives for those institutions. ${ }^{27}$

However, this is only a partial set of remedies that might be applied progressively to financial institutions in each category. Naturally, the exact regulatory treatments and the nature of the increased supervisory attention call for additional study. As a system of regulatory

the same as tier 1 of the Cleveland Federal Reserve's tiered-parity proposal. See Sandra Pianalto, Ohio Banker's Day Address: Steps Toward a New Financial Regulatory Architecture 3-4 (Apr. 1, 2009) (explaining the "tiered parity" scheme), available at http://www.clevelandfed.org/ For_the_Public/News_and_Media/Speeches/2009/Pianalto_20090401.cfm.

26. See generally Rong Fan et al., Getting the Most Out of a Mandatory Subordinated Debt Requirement, 24 J. OF FIN. Servs. Res. 149 (2003) (discussing mandatory subordinated debt requirements); see also generally Mark J. Flannery, Stabilizing Large Financial Institutions with Contingent Capital Certificates (October 6, 2009) (unpublished article, University of Florida) (discussing reverse convertible debentures), available at http://ssrn.com/abstract=1285689.

27. See Edward J. Kane, No Room for Weak Links in the Chain of Deposit Insurance Reform, 1 J. of Fin. Servs. Res. 77, 89 (1987). 
taxes progressive systemic mitigation is subject to the regulatory dialectic . Consequently, it is important to understand the unintended consequences of whatever treatments are adopted. ${ }^{28}$ Such an understanding will help reduce the deadweight losses of the regulatory regime and increase regulators' ability to respond dynamically to an evolving financial system.

\section{Transparency Versus Constructive Ambiguity: Should the List of SIFIs Be Public?}

How much information is made public (details about SIFIs, criteria for inclusion in the categories, and the associated regulatory treatment) depends on several factors: the extent to which the supervisory regime utilizes market discipline; whether inclusion on the list has unintended certification effects (or, alternatively, whether ambiguity reduces the credibility of implicit government guarantees); and the degree to which markets can reliably identify the financial institutions that populate the categories. ${ }^{29}$ The more information is releasedthat is, the closer the regime is to full disclosure-the more side issues must be addressed. For instance, how will an institution's inclusion in - or removal from - the list of SIFIs or the promotion (demotion) to a higher (lower) category be communicated? Will there be watch lists of SIFIs that are under consideration for change in status? Would the names of firms that are systemically important because of context/ conditions be made public? If made public, what additional information (such as risk models, scenario analysis, and simulations) should be provided?

The choice of disclosure regime would seem to be between transparency (publication of the list of firms in each category) and some version of constructive ambiguity, where selected information is released. The term "constructive ambiguity" has been attributed to former Secretary of State Henry Kissinger. ${ }^{30}$ In a diplomatic context, it refers to the use of ambiguous statements as part of a negotiating strategy; however, in the context of central banking and financial markets, the term refers to a policy of using ambiguous statements to sig-

28. See Edward J. Kane, Good Intentions and Unintended Evil: The Case against Selective Credit Allocation, 9 J. OF MONEY, CrediT, \& BANking 55, 57 (1977) (discussing the regulatory dialectic).

29. See generally Allen Berger et al., Comparing Market and Supervisory Assessments of Bank Performance: Who Knows What When?, 32 J. of Money, Credit, \& Banking 641 (2000) (analyzing how markets discover regulatory information).

30. John Linarelli, China and the GATT Agreement on Government Procurement, 8 J. CHINESE L. 185, 224 (1994) (citing Peter G. Peterson, Address at the China Business and Financial Symposium sponsored by China Daily (May 4, 1994)). 
nal intent while retaining policy flexibility. In the context of the federal financial safety net, many have argued for a policy of constructive ambiguity to limit expansion of the federal financial safety net. ${ }^{31}$ The notion here is that if market participants are uncertain whether their claim on a financial institution will be guaranteed, they will exert more risk discipline on the firm. In this context, constructive ambiguity is a regulatory tactic for limiting the extent to which de facto government guarantees are extended to the liabilities of the firms that regulators consider systemically important. Uncertainty about whether a firm is considered systemically important and which category it belongs to in the progressive systemic mitigation regime may, at the margin, exert stronger market discipline on institutions than if the list of SIFIs were made public.

A policy of supervisory transparency is superior to constructive ambiguity for our purposes for a number of reasons. First, when broadly viewed, constructive ambiguity is a competitor of the progressive systemic mitigation regime proposed in this paper. Constructive ambiguity is a supervisory policy aimed at reducing the agency problems associated with firms' systemic importance by creating uncertainty about which firms and creditors might be rescued if a firm fails. Progressive systemic mitigation is an explicit set of regulations and supervisory policies designed to reduce (if not eliminate) the advantages of being systemically important. Under its rules, the institution and its stakeholders would internalize the social costs of systemic importance. Second, to the extent that SIFIs would be subject to specific sets of regulatory treatments, it is unlikely that there would be much value in continuing the policy of constructive ambiguity in the proposed progressive systemic mitigation system. After all, markets will probably be able to surmise which firms are on the SIFI list by observing differences in capital structure, balance sheet entries (including footnotes), and intensity of regulatory scrutiny. Third, increased transparency would improve supervisory accountability, better aligning supervisory incentives with the interests of taxpayers. Finally, the benefit of constructive ambiguity in avoiding a SIFI certification, resulting from publishing a list of SIFI firms, would only affect a small number of firms at the margin. The efficiency gains of avoiding the certification

31. See generally Frederic S. Mishkin, Financial Consolidation: Dangers and Opportunities, 23 J. OF BANKING \& Fin. 675 (1999) (discussing constructive ambiguity as a tool for limiting conjectural government guarantees of bank creditors); see generally Marvin Goodfriend \& Jeffrey M. Lacker, Limited Commitment and Central Bank Lending, 85 FED. RES. BANK OF RICHMOND ECON. Q. 1 (1999) (discussing constructive ambiguity in the context of lender-of-last-resort policies). 
effect on these marginally systemic firms is likely to be overcome by efficiency losses associated with withholding information from the market. Hence, the list of SIFIs, including categories and criteria for inclusion, should be made public, along with a watch list of financial institutions whose SIFI status might change.

An effective system of supervisory transparency entails more than simply disclosing information; it must also include producing information and disseminating it in a useful form. ${ }^{32} \mathrm{~A}$ case on point is the argument for requiring credit rating organizations to disclose information, such as probabilities of default and loss given default, upon which a rating is based..$^{33}$ In the supervisory transparency regime, this means that all information used to assign institutions to an SIFI category-including supervisory risk models and their results-should be disclosed. ${ }^{34}$ Furthermore, stress tests of SIFIs, along with contingency plans for handling the financial distress of one or more large financial institutions, should be implemented and disclosed.

\section{Conclusions and Policy Recommendations}

The legacy of economic and financial crises is a post-crisis regime characterized by increased government interference in markets. However, simply increasing the amount of formal regulation and the degree of supervisory oversight and interference is not necessarily the best path forward. Financial market reforms must deal in the most cost effective way with the fundamental issues that contributed to the current crisis. One of the most important issues that regulators, legislators, and other policymakers must face is that of systemically important financial institutions.

This Article proposes the study and subsequent adoption of a financial market supervisory infrastructure in which SIFIs are identified and categorized according to the nature or source of their systemic importance, and subjected to specific regulatory treatments that ad-

32. See Board of Governors of the Federal Reserve System, 2001, SR 01-6: Enhancement to Public Disclosure, Division of Banking Supervision, April (proffering the recommendations of the 2001 Working Group on Public Disclosure, which suggests that supervisors release information, such as data about risk exposure, that provides a consistent view of a bank's risk management approach), available at http://www.federalreserve.gov/boarddocs/srletters/2001/sr0106.htm.

33. See Charles W. Calomiris, "The Subprime Turmoil: What's Old, What's New, and What's Next" Presentation at the Federal Reserve Bank of Kansas City's Symposium: Maintaining Stability in a Changing Financial System 20 (Aug. 21-22, 2008), available at http://www.kc.frb.org/ publicat/sympos/2008/Calomiris.10.02.08.pdf.

34. In cases where releasing a piece of information could result in the disclosure of confidential business information, suppression of the information should be predicated on a careful costbenefit analysis, which weighs the financial institution's private interests against the benefits to society. 
dress the risk these firms impose. The ultimate objective of progressive systemic mitigation is to improve economic efficiency by promoting socially compatible risk incentives for SIFIs and increase fairness in the financial system by leveling the playing field. The means to achieve this is to reduce or remove, through regulatory taxes, the advantages of being systemically important.

Specific regulatory treatments to deal with the "four C's" of systemic importance (contagion, correlation, concentration, and context/ conditions) must be carefully studied before they are adopted. These regulatory treatments might include, but are not limited to the following: capital surcharges, special reserves, mandatory subordinated debt and/or reverse capital debentures, inter-firm exposure limits, and increased regulatory reporting requirements. Moreover, banking supervisors should be required to conduct periodic systemic risk analyses, stress tests, and other simulations as part of a contingency planning process. This would improve regulators' ability to deal in the most cost effective manner (combined short- and long-term costs) with the failure of one or more SIFIs. Finally, the information disclosure regime must be addressed when implementing the new supervisory architecture. This article argues for full transparency, which includes publishing the list of SIFIs, presumably on a quarterly basis. The criteria for inclusion in an SIFI category should be disclosed as well as the specific regulatory treatments. In addition, financial institutions whose systemic status may be upgraded or downgraded should be included on a published watch list.

In conclusion, this scheme envisions a financial market supervisory infrastructure where systemically important financial institutions are identified, separated into categories based on nature of their systemic importance, and subjected to specific regulatory treatments designed to address the systemic risk these firms impose. The ultimate objective is to promote socially compatible risk incentives for systemically important financial institutions and fairness in the financial system by leveling the playing field - by reducing or removing, through regulatory taxes, the advantages associated with being systemically important. Transparency is an important part of any supervisory system because it allows for more effective market discipline and increased supervisory accountability. 